\title{
Online Survey Study on COVID-19 Vaccination Awareness in Indian Population
}

\author{
Jyoti Arya $^{1 *}$, Swati Patel ${ }^{2}$ \\ ${ }^{1}$ Assistant Professor, Department of Zoology, Vedic Balikapg College, University of Rajasthan, Jaipur, India \\ ${ }^{2} \mathrm{HOD}$, Department of Physiotherapy, Fortis Hiranandani Hospital, Navi Mumbai, India
}

\begin{abstract}
*Address for Correspondence: Dr. Jyoti Arya, Assistant Professor, Department of Zoology, Vedic Balikapg College, University of Rajasthan, Jaipur, India
\end{abstract}

E-mail: arorajyoti623@gmail.com

Received: 24 Dec 2020/ Revised: 21 Feb 2021/ Accepted: 05 Apr 2021

\begin{abstract}
Background: Corona virus disease (COVID-19) has affected more than 200 countries causing loss of life. The development of the COVID-19 vaccine is a great evolution, and data suggests that is safe and effective. However, we have planned to assess the awareness, attitude and acceptance of the vaccine.

Methods: A survey monkey was conducted among 135 people to evaluate the level of awareness regarding COVID-19 vaccination and to manage myths after having it.

Results: The result revealed that some percentages of the population were familiar about vaccination. It should be taken to prevent the severity of symptoms of COVID-19. Some age group were scared about the side effects and the vaccine may not be enough efficient to battle the coronavirus.

Conclusion: Having insight on the percentage of people, who was not aware of the effects and efficacy of the vaccine. This survey would help the general population to understand and disperse the side effects and motivate every age group to take the COVID-19 vaccine and get aware to keep them safe from the virus.
\end{abstract}

Key-words: Antibody, Ayurvedic medicine, Covid-19, Immune system, Pandemic, Survey, Vaccine

\section{INTRODUCTION}

Coronavirus has affected people all over the world. The earliest date of onset was $1^{\text {st }}$ December 2019 in Wuhan city, china expanded its circle in South Korea, Italy, Iran, Japan and spreading to India with the large population affected $^{[1-4]}$. The WHO declared this pandemic on March 11-2020 [5]. This pandemic will begin to inflict huge morbidity and death rate pressures so the worldwide population and economy are seriously affected. COVID19 is a highly infectious disease caused by a novel coronavirus. The name corona was given because of its appearance of the spikes on its surface that resembles to crown ${ }^{[6]}$. Initially, it spreads throughout the respiratory tract by droplets (cough and sneeze), respiratory

\section{How to cite this article}

Arya J, Patel S. Online Survey Study on COVID-19 Vaccination Awareness in Indian Population. SSR Inst. Int. J. Life Sci., 2021; 7(3): 2818-2826.

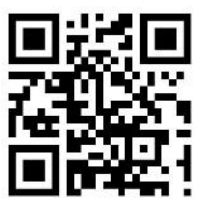

Access this article online https://iijls.com/ secretion and direct contact ${ }^{[7,8]}$. The virus can survive on the contaminated surfaces for about 72 hours. Now this pandemic is rapidly affecting all sectors of the world, it escalates the health system and distributed the daily life protocol all over the world's population. As of $24^{\text {th }}$ February 2021, there have been 112 million confirmed cases of COVID-19 and 2.5 million deaths worldwide. India is also severely affected because of its vast population density which is more than 1.3 billion and that is the reason India is the second maximum COVID19 affected country after the USA. Now we are in the phase where the COVID-19 is re-spreading at a large scale and vaccination is only a solution to control this pandemic. It is very well known in some studies that vaccine uncertainty and disinformation in several countries creates extensive challenges to the attainment of coverage and population immunity ${ }^{[9,10]}$. So vaccine provides the best hope for a permanent solution to controlling the disease and the awareness of the disease among the people will probably have an important role in fighting against this pandemic. 
This survey is particularly important concerning India because the country has a variety, literacy rate, topography and climate and awareness is one of the ways of the fight against this pandemic. An online survey has become an important tool for COVID-19 research because conventional survey methods are not feasible. Thus this survey study aimed to investigate community knowledge, understanding and awareness towards the COVID-19 vaccine in different parts of India.

\section{MATERIALS AND METHODS}

Due to the limitations doing face to face research during this pandemic era, this study was conducted using an online survey questionnaire, which was circulated

Table 1: Survey Questionnaire of vaccination awareness through social media and online electronic mail. The survey contains 20 questions with multiple choices.

This online survey response was collected from January to March 2021. Each and every individual of different cities of India of all age-group were involved in this survey including students, healthcare professionals, employed and unemployed persons.

The survey evaluation was done electronically using the interface provided by the common survey software conducting site available on the internet.

\begin{tabular}{cc}
\hline S.No & Entity \\
\hline 1. & How do mRNA vaccines work?
\end{tabular}

2.

Who should not get the COVID-19 vaccine?

3.

What are the side effects of mRNA vaccine?

4.

Can a person take medicine for the side effects after getting the

vaccine?

How many days of quarantine period are required after getting

5.

6.

$$
\text { infected from corona virus? }
$$

Are young children susceptible to COVID-19, especially if a parent

tests positive?

How many doses of a COVID-19 vaccine will be needed?

7.

8.

If you had the virus, will you still need to get the vaccine?

Can pregnant women get the COVID-19 vaccine?

9.

10.

11.
A person currently taking antibiotics, can he/she take the COVID-

$$
19 \text { vaccine? }
$$

Who will get the vaccine first?
Options (\%)

Spike protein (77\%)

Collagen (23\%)

Current symptoms(77\%)

Elderly people(23\%)

Fever (88.90\%)

Vomiting (11.10\%)

Yes (76.30\%)

No (23.70\%)

14 days $(93.30 \%)$

7 days (6.70\%)

Yes $(80.70 \%)$

No (19.30\%)

Two (89.60\%)

Three (10.40\%)

Yes (85.90\%)

No (13.30\%)

Yes $(21.50 \%)$

Unclear (78.50\%)

Yes (76.30\%)

No $(23.70 \%)$

Doctors (97.80\%)

Students (2.20\%) 
12.

Does pneumonia vaccine work against coronavirus?

13.

14.

15.

16.

Will a photo/ ID be required at the time of registration?

If a person is having Cancer or hypertension, can they take COVID-

17.

18.

19.

Are there any preventive measures and precautions that one

$$
\text { needs to follow at the session site? }
$$

When would antibodies develop after vaccination?

20.
Doctors $(97.80 \%)$

Students (2.20\%)

Yes (23.7\%)

No (76.3\%)

Yes (45.9\%)

No (54.1\%)

Compulsory (28.1\%)

Voluntary (71.9\%)

Yes (95\%)

No $(5 \%)$

Yes (61.5\%)

No (38.5\%)

Rest 30 min (78.5\%)

Leave immediately(21.5\%)

After $1^{\text {st }}$ Dose $(40 \%)$

After $2^{\text {nd }}$ Dose $(60 \%)$

Immunity booster(96.3\%)

Sleep (3.7\%)

\section{RESULTS}

A total of 135 responses from all over India are received. The respondents have adequate awareness for COVID-19 vaccination and other preventive measures. Results of participants' awareness against COVID-19 summarized in Fig. 1 to Fig. 20.

Total $77 \%$ of respondents were aware of how mRNA vaccine works, they are known about the process of protein that was presented inside the human body, which has a major role in cases of COVID-19. While on the other hand $23 \%$ doesn't know about the COVID vaccine is to be taken with antibiotics or other medications. At the same time, $40 \%$ of people don't know after which dose of vaccine of our body will generate antibodies that will help to get us saved from the virus.

Total $88.9 \%$ to $90 \%$ of participants were very much conscious about the side effects and doses of COVID-19 vaccination, but $5 \%$ to $6 \%$ of people were not aware of protocol that used at the vaccine centres. Total $80.7 \%$ of respondents were informed about the susceptibility to COVID-19 for young children and $23.7 \%$ people were unaware of taking medicines for the side-effects after getting vaccinated. Total $76.3 \%-73.3 \%$ people were enough sensible about the fact that vaccine given for pneumonia or flu is not beneficial for COVID-19. Total $61.5 \%$ participants were acquainted with patients who are already suffering from cancer or hypertension can safely take COVID-19 vaccine, on the other part $54.1 \%$ people were not aware about that breastfeeding mothers can be included in the same category as they are also at a higher risk, even baby may also benefit from antibodies through breast milk as per the studies. Total 96.3\% respondents were familiar with the benefits of homeopathic/ Ayurvedic medicines that helped people a lot to boost their immune system. Total $71.9 \%$ respondents are aware to take the vaccine even $85.9 \%$ people know that they should get the vaccine still after they had virus but $78.5 \%$ were unclear about the vaccination in pregnant women. Total $93.3 \%$ participants have knowledge about the quarantine period after getting infected from virus on other part $21.5 \%$ people were not aware about preventive measures and precautions at the session site. Total $89.6 \%$ respondents believe that two doses of vaccine were required and 
$97.8 \%$ people very well know the priority of persons getting the vaccine on other hand $23 \%$ were not aware

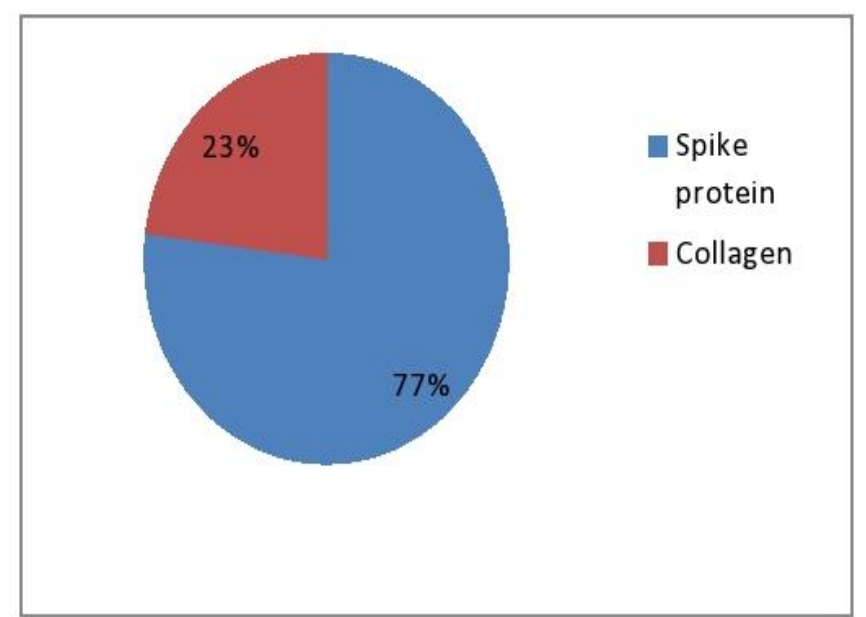

Fig. 1: How do mRNA vaccines work?

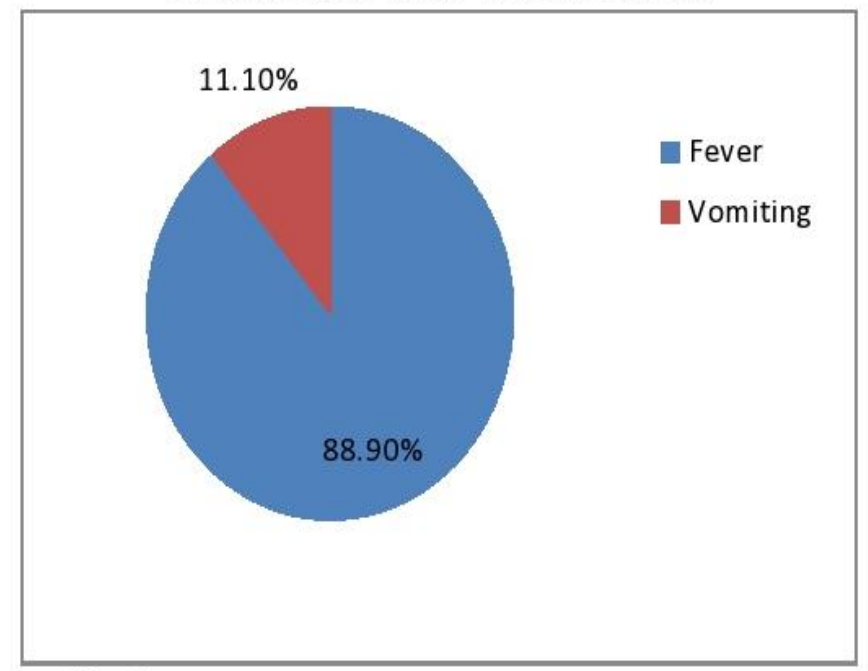

Fig. 3: What are the side effects of mRNAvaccine?

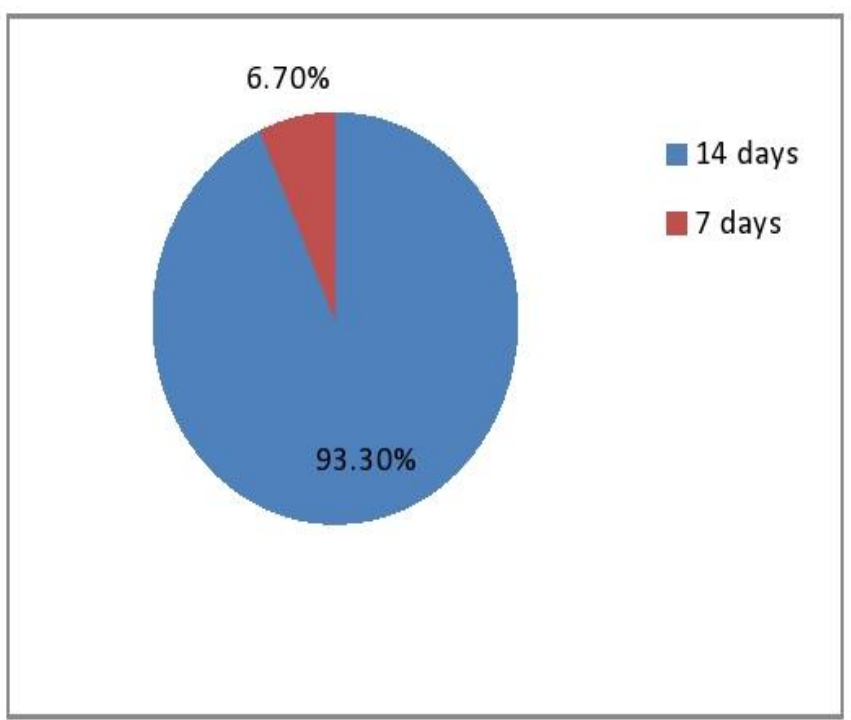

Fig. 5: How many days of quarantine period are required after getting infected from corona virus? about that who should not get the vaccine of COVID-19.

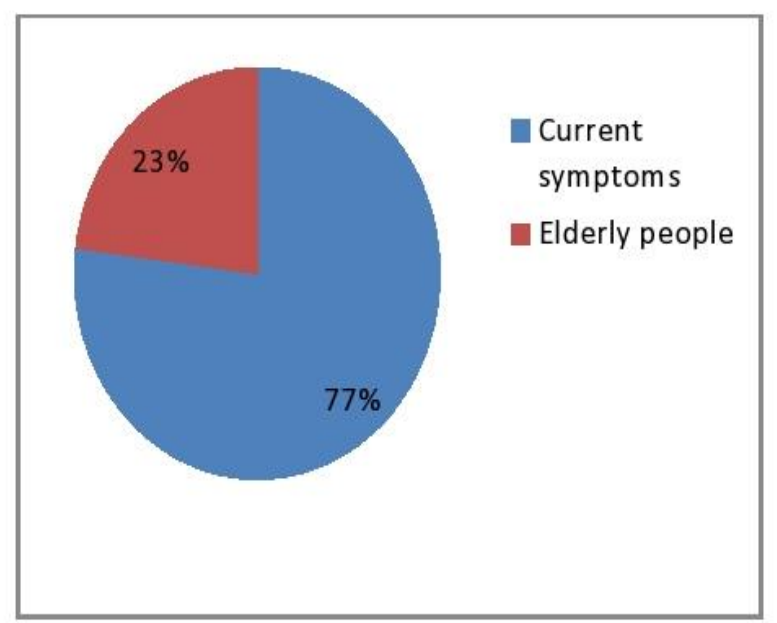

Fig. 2: Who should not get the COVID- 19vaccine?

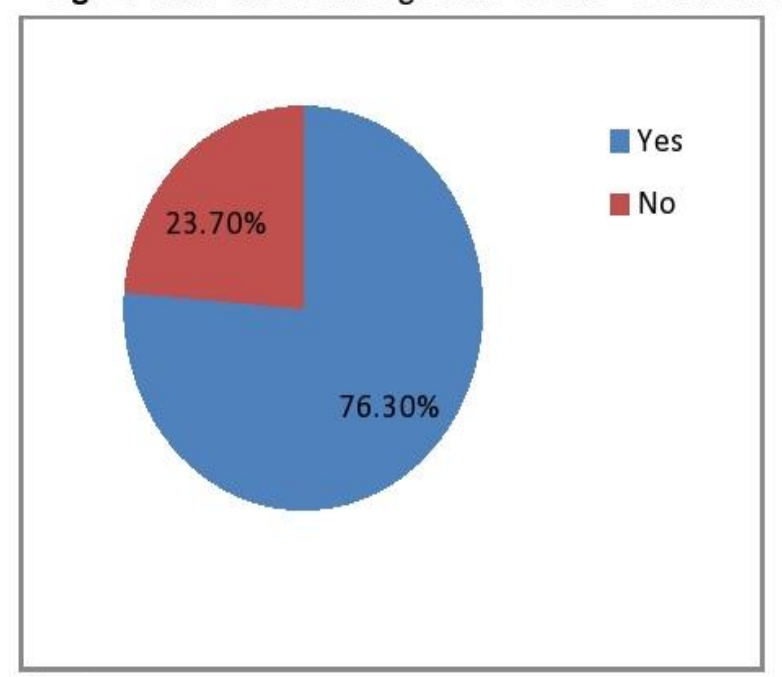

Fig. 4: Can a person take medicine for theside effects after getting the vaccines?

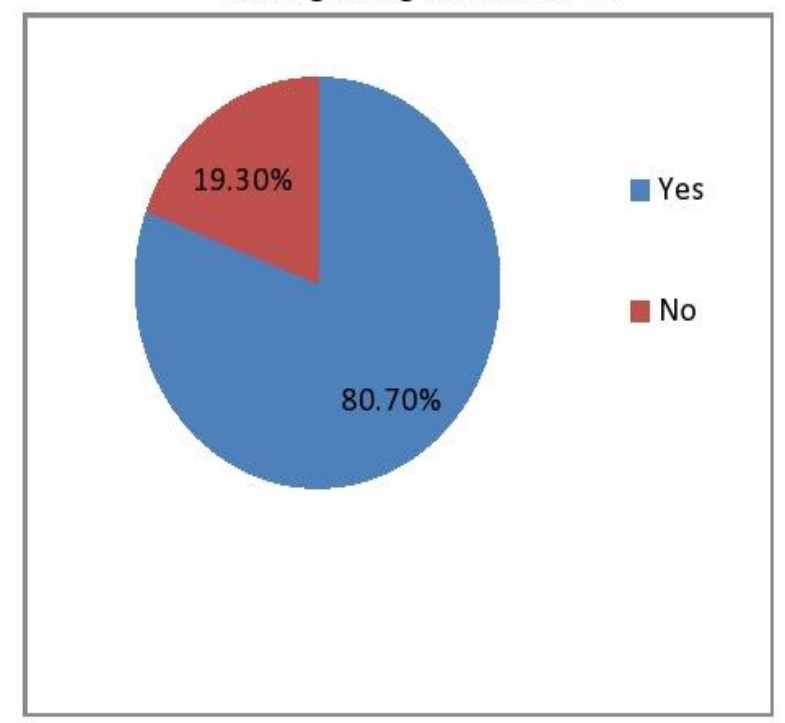

Fig. 6: Are young children susceptible to COVID-19, especially if a person tests positive? 


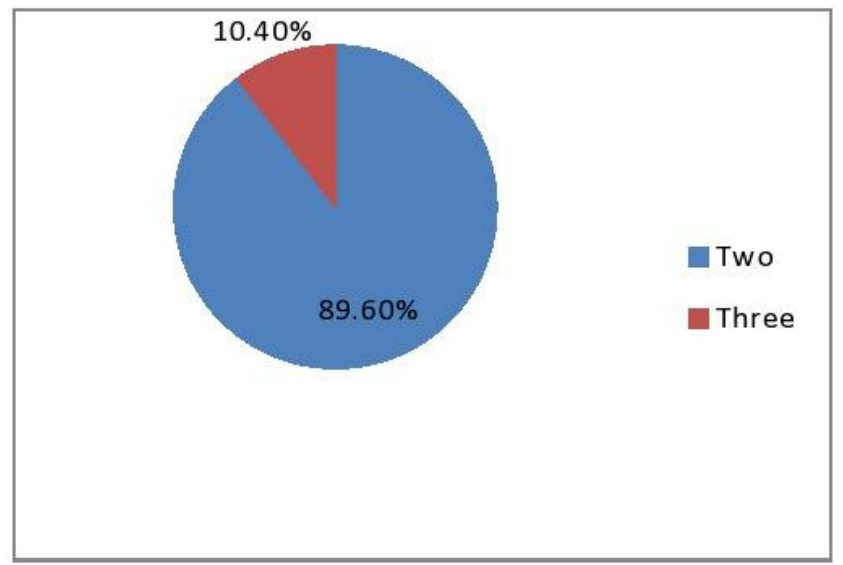

Fig. 7: How many doses of a COVID- 19 vaccinewill be needed?

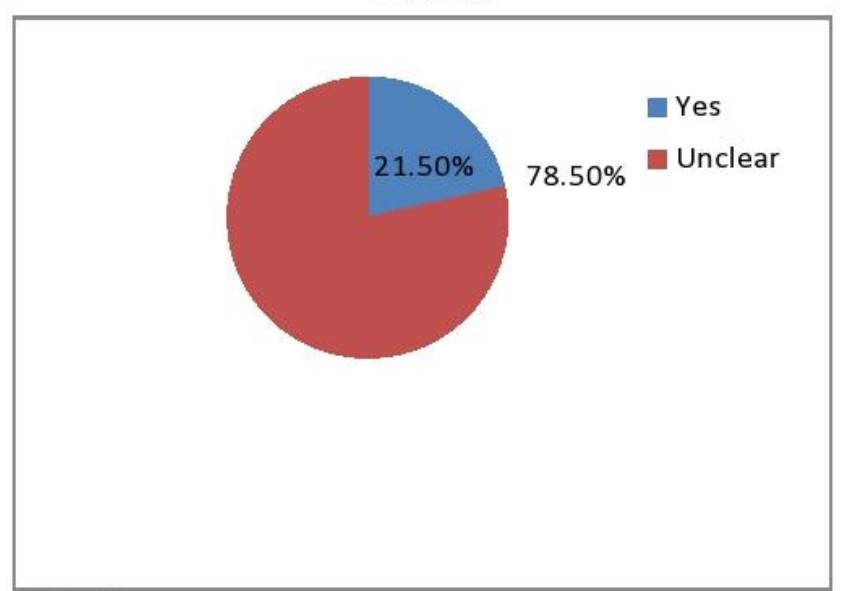

Fig. 9: Can pregnant women get the COVID-vaccine?

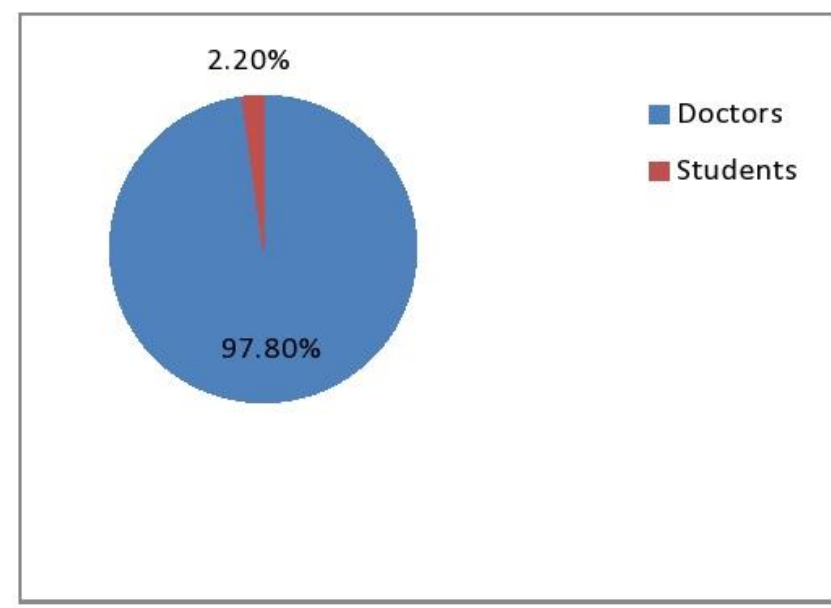

Fig. 11: Who will get vaccine first?

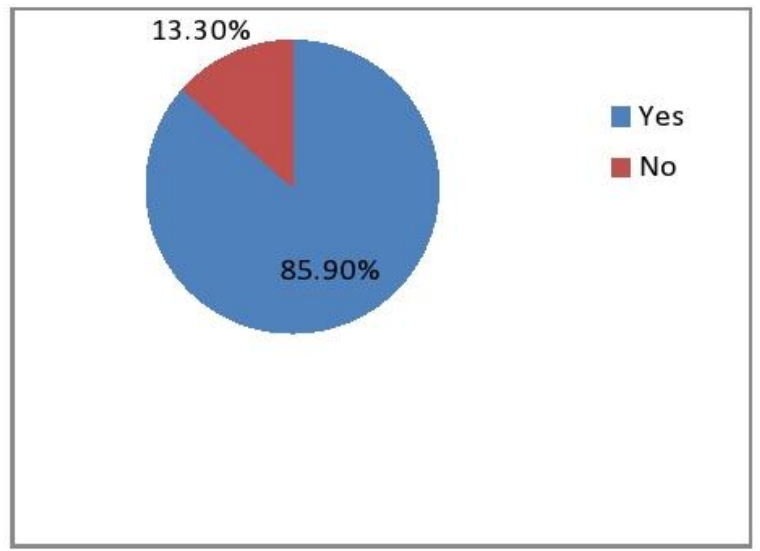

Fig. 8: If you had the virus, will you stillneed to get the vaccine?

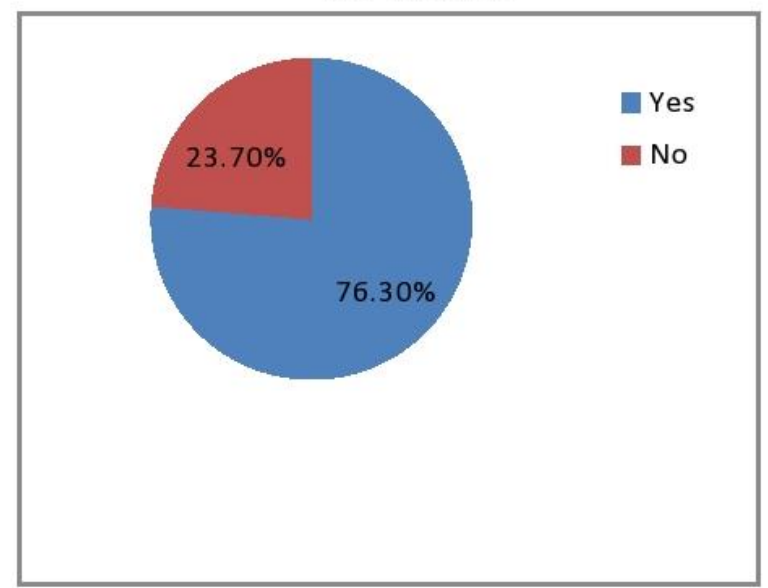

Fig. 10: A person currently taking Antibiotics can He/She take the COVID-19vaccine?

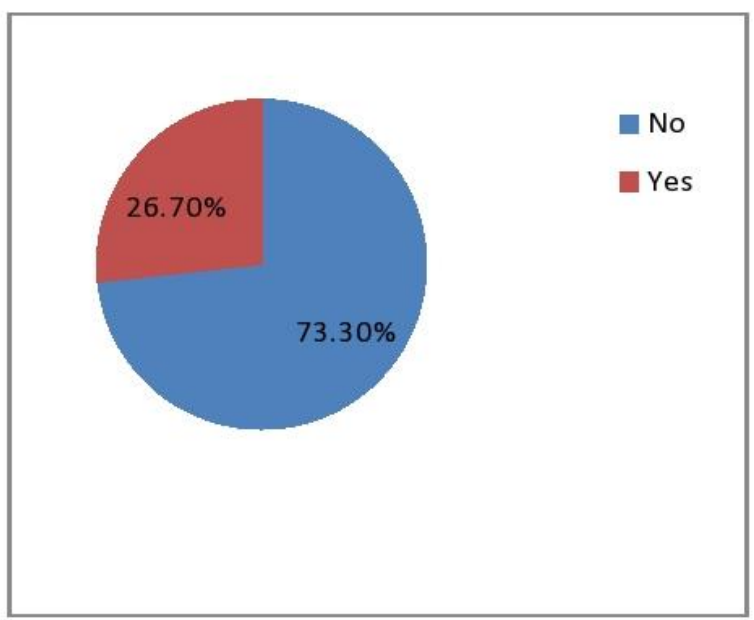

Fig. 12: Does pneumonia vaccine workagainst coronavirus? 


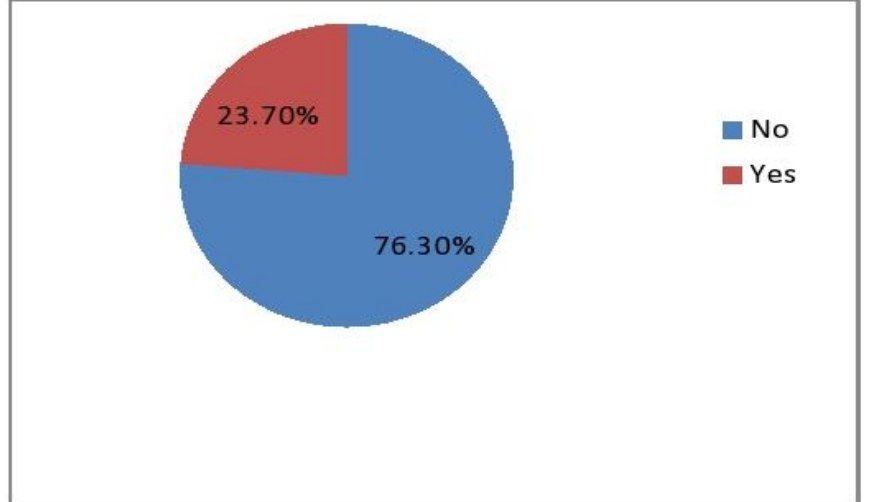

Fig. 13: Will getting the FLU vaccine protectsagainst coronavirus?

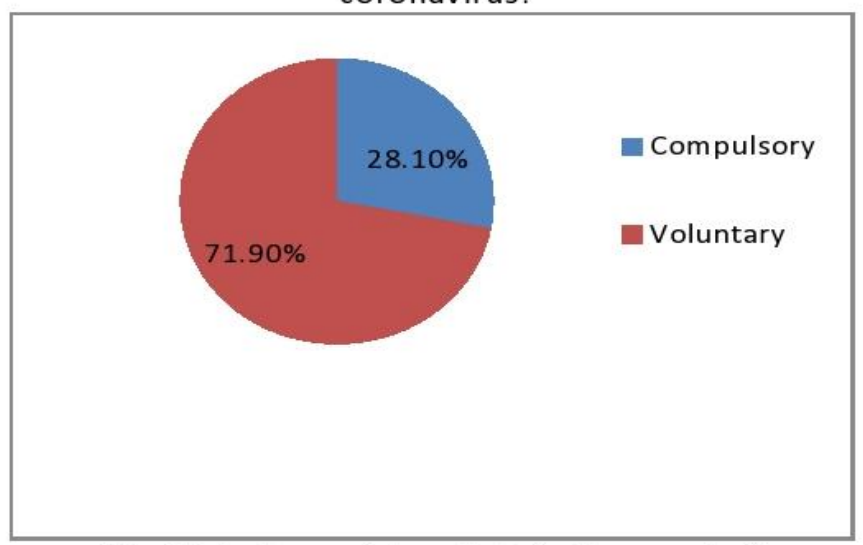

Fig. 15: Is it mandatory to take the vaccine?

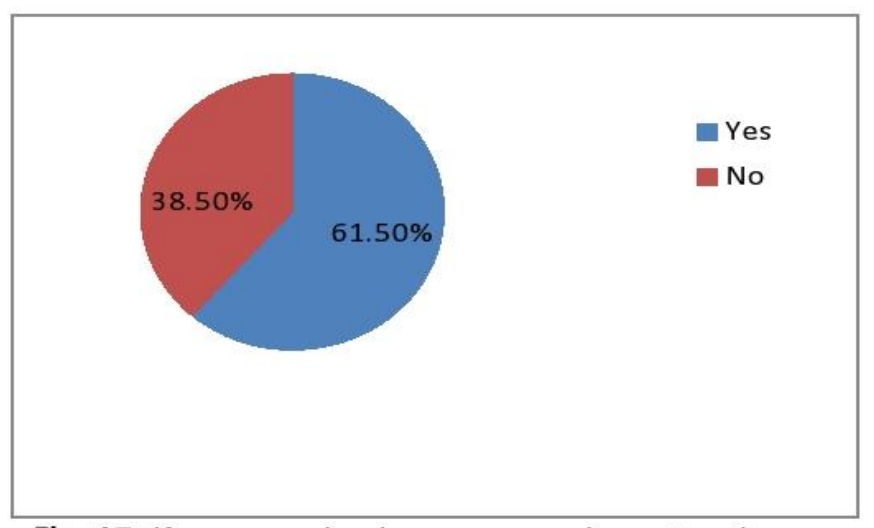

Fig. 17: If a person having cancer or hypertensioncan they take COVID-19 vaccine?

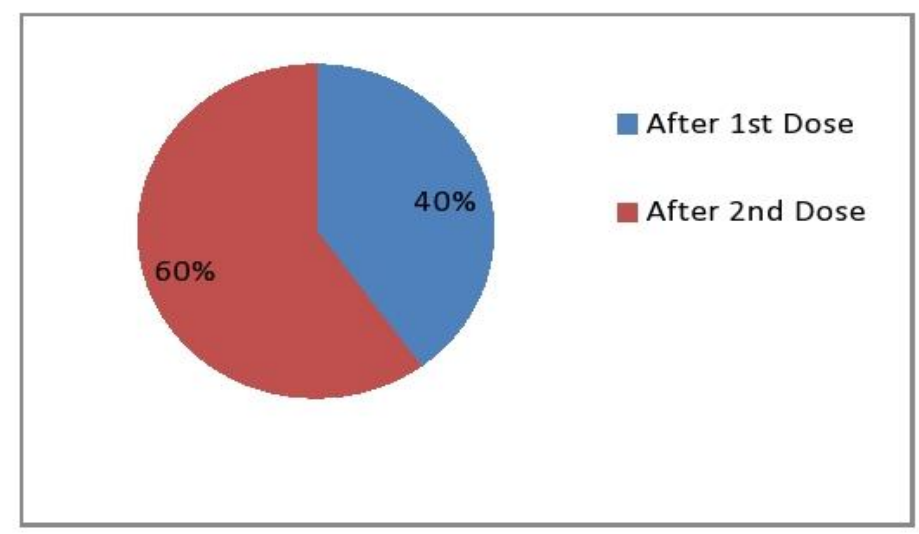

Fig. 19: When would antibodies develop after vaccination?

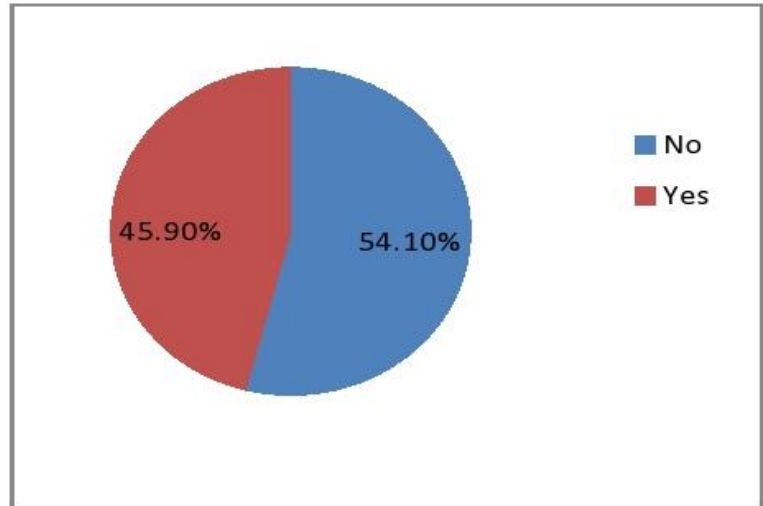

Fig. 14: Can a breastfeeding take theCOVID-19 vaccine?

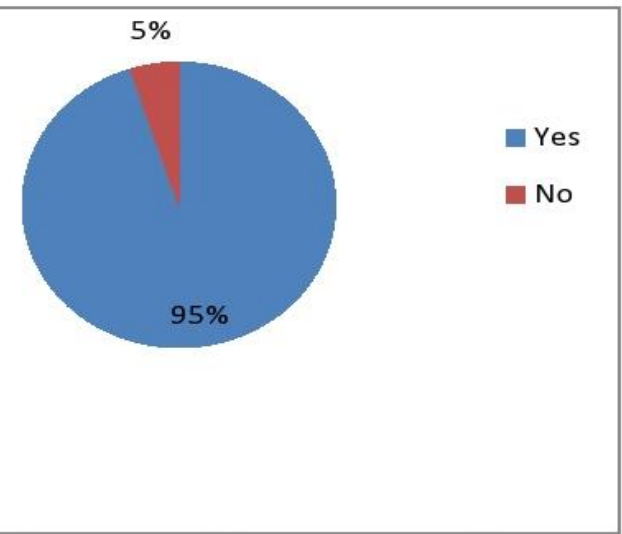

Fig. 16: Will a photo/ ID be required at thetime of registration

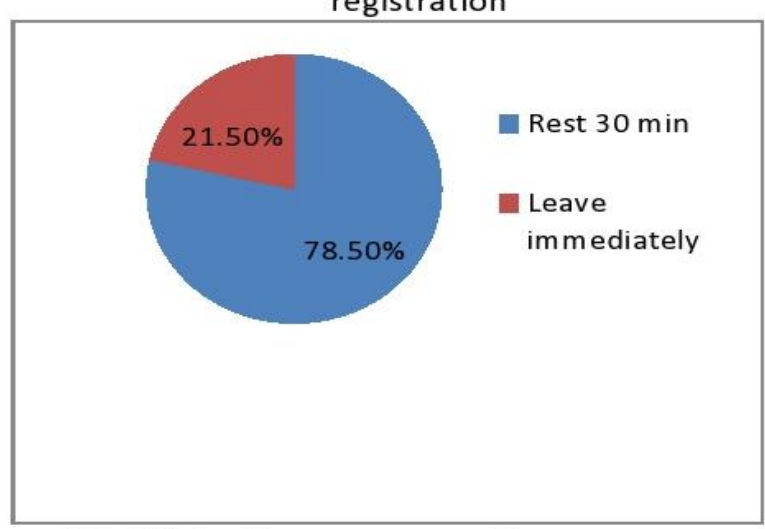

Fig. 18: Are they any preventive measuresand precautions that one needs to follow atthe session site?

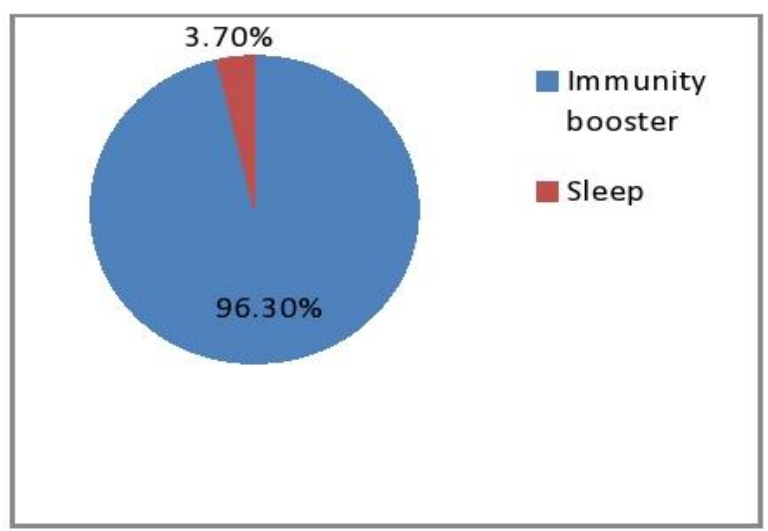

Fig. 20: What is the role of homeopathic/ ayurvedic medicines in preventing corona virus? 


\section{DISCUSSION}

The study was conducted to find out the awareness among different age group all over India which particularly important to evaluate the knowledge of peoples regarding the information about COVID-19. Due to some limitations, we made an online survey. We saw that most of the respondents were conscious about the side effects of the vaccine but were not aware of how to manage those side effects with what kind of medication. Aged people and with various co-morbidities like cardiovascular diseases, diabetes, acute/ chronic respiratory diseases, autoimmune conditions and other different problems are more likely to develop serious illness ${ }^{[11]}$. The best way to prevent transmission is to know about how the virus spreads. According to the data from the US vaccine adverse event reporting system (VAERS), $80 \%$ of the people have experienced side effects such as injection-site pain, fatigue, lethargy. These symptoms could be an indication that the body is developing the desired immunity for protection ${ }^{[12,13]}$. These vaccines are delivered in a two-dose regimen, the first dose triggers the immune response and the second dose is a booster dose that strengthens the body's immune system to fight against the coronavirus and is our respondents were well informed about the development of immunity after the second dose of vaccination $^{[14]}$.

Another point we analyzed in this study that respondents were aware of vaccine given for flu or pneumonia was not beneficial in coronavirus but According to Skylar [15] (Flu vaccine may protect against covid-19 infection), patients who received the flu vaccine were found to have $24 \%$ of lower odds of testing positive for coronavirus. Additionally, people who were vaccinated against flu and tested positive for COVID-19 were more likely to have better clinical outcomes. Even we have seen the outcomes of ayurvedic interventions in coronavirus patients or building their immunity to get protected against the virus in some studies [16,17]. Patients, who were taking ayurvedic medicines with various symptoms such as fatigue, cough, loss of taste and smell, nasal block and headache showed impressive clinical improvements. In this study, most of the respondents accepted ayurvedic medicines as an immunity booster in preventing this disease. Earlier there was not much data available for breastfeeding mothers should take the vaccine or not, but UK joint committee on vaccination and immunization (JCVI), now advises that there is no known risk in giving these vaccines to breastfeeding women ${ }^{[18]}$. This pandemic has made an adverse impact on people's life ${ }^{[19-22]}$. Currently, one of the important discussions is the prevention of coronavirus infection through the COVID-19 vaccine. There are multiple sources of information ranging from scientific researches to social media providing contrary information which is leading to confusion among the general public ${ }^{[23]}$. Vaccines save many lives each year. They help the body's immune system to recognize and fight the viruses and bacteria they target. WHO has been working in collaboration with scientists and global health organizations for the fast development of vaccines, and control of the spread of the virus.

\section{CONCLUSIONS}

People have mixed viewpoints regarding the COVID-19 vaccine. Directing correct information may improve people's preparedness about vaccination. Internet and Media plays an important role in educating and spreading awareness about the post-effects of the vaccine in a correct way so that people have a positive attitude. Utilizing these can help increase awareness among people, and improve the health consequences of the population.

So for prospects, we can take the vaccine as a major role in controlling the severity of infection, this article may give proper awareness and positive feedback to the Indian population to be vaccinated.

\section{CONTRIBUTION OF AUTHORS}

Research concept- Dr. Jyoti

Research design- Dr. Jyoti, Dr. Swati

Supervision- Dr. Jyoti

Materials- Dr. Jyoti, Dr. Swati

Data collection- Dr. Jyoti, Dr. Swati

Data analysis and Interpretation- Dr. Jyoti

Literature search- Dr. Jyoti, Dr. Swati

Writing article- Dr. Jyoti, Dr. Swati

Critical review- Dr. Swati

Article editing- Dr. Swati

Final approval- Dr. Jyoti, Dr. Swati 


\section{REFERENCES}

[1] Mitchell EP. Corona Virus: (Global Pandemic Causing World-Wide Shutdown). J Natl Med Assoc., 2020.

[2] Zhang HW, Yu J, Xu HJ, Lei Y, Pu ZH, et al. Corona Virus International Public Health Emergencies: Implications for Radiology Management. Acad Radiol., 2020; 27: 463-67.

[3] Li A, Guan X, Wu P, Wang X, Zhou L, et al. Early transmission dynamics in Wuhan China of novel coronavirus- infected pneumonia. New Eng J Med., 2020; 382: 1199-207.

[4] Wu JT, Leung $K$ and Leung GM. Nowcasting and forecasting the potential domestic and international spread of the 2019-ncov outbreak originating in Wuhan, Chiana: A modelling study. The Lancet, 2020;395(10225):689-97.

[5] WHO, 2020c. Rolling updates on coronavirus disease (COVID-19) retrieved

from https://www.who.int/emergencies/diseases/no vel-coronavirus-2019/events-as-they-happen.

[6] Wang L, Wang Y, Ye D, Liu Q. A review of the 2019 Novel Coronavirus (COVID-19) based on current evidence. Int J Antimicrob Agents, 2020A; 56(3): 106137.

[7] Wang J, Du G. Covid 19 may transmit through aerosol. Ir. J. Med. Sci. 2020; 189(4): 1143-44.

[8] Madas B.G, Furi P, Farkas A, et al. Decomposition distribution of the new coronavirus(SARS-CoV-2) in the human airways upon exposure to cough droplets and aerosol particles. Sci Rep., 2020; 10: 22430.

[9] Larson HJ, Jarrett C, Eckersberger E, Smith DM, Paterson D. Understanding vaccine hesitancy around vaccines and vaccination from a global perspective: $A$ systematic review of published literature, 20072012. Vaccine, 2014; 32: 2150-59.

[10]Lane S, MacDonald NE, Matri M, Dumolard L. Vaccine hesitancy around the globe: analysis of three years of WHO/UNICEEF joint reporting from data, 2015-2017. Vaccine, 2018; 36: 3861-67.

[11]Wu Z, Mc Googan JM. Characteristics of and important lessons from the coronavirus disease 2019 (COVID-19) outbreak in China: Summary of a report of 72314 cases from the Chinese center for disease control and prevention. JAMA, 2020; 323: 1239-42.

[12]Centers for disease control and prevention. What to expect at your appointment to get vaccinated for COVID-19, CDC Vaccines, 2021.
[13] Mingxiang Y, Dian F, Yi Ren, Faxiang W, Dong W, et al. Treatment with convalescent plasma for COVID19 patients in Wuhan, China. J Med Virol., 2020; 92(10): 1890-901.

[14] Kezia P. Covid-19 vaccine mixing: The good, the bad and the uncertain. Clinical Trials ARENA, 22-04-2021. http://www.clinicaltrialsarena.com.

[15]Skylar J. Flu vaccine may protect covid-19 infection: Am J Managed care, 2021; https://www.ajmc.com/view/flu-vaccine-mayprotect-against-covid-19-infection.

[16]Jyoti AJ, Rammanohar P. Outcomes of Ayurvedic care in a covid-19 patient with hypoxia-A case report. J Ayurveda Integr Med., 2020; 10.006.

[17]Tillu G, Chaurvedi S, Chopra A, Patwardhan B. Public health approach of Ayurveda and yoga for COVID-19 prophyaxis. J Altern Complement Med., 2020; 26(5): 360-64.

[18]Royal college of obstetricians \& Gynaecologists (RCOG). Update advice on covid-19 vaccination in pregnancy and women who are breastfeeding. News 30 December, 2020.

[19] Kumari, P. Ranjan, K.A. Sharma, A. Sahu, J. Bharti, R., etal.Impact of COVID-19 on psychosocial functioning of peripartum women: a qualitative study comprising focus group discussions and in-depth interviews. Int J Gynaecol Obstet., 2021; 152(3): 321-27.

[20]Mazumder A, Bandhu KK, Sarkar S, Ranjan P, Sahu $A$, et al. Psycho-social and behavioural impact of COVID 19 on young adults: qualitative research comprising focused group discussion and in-depth interviews. Diabetes Metab Syndr., 2021; 15(1): 30912.

[21]Ranjan P, Kalanidhi KB, Kaur D, Sarkar S, Sahu A, et al. Psycho-social and behavioral impact of COVID-19 on middle-aged and elderly individuals: a qualitative study. J Educ Health Promot., 2021.

[22]Chopra S, Ranjan P, Singh V, Kumar S, Arora M, et al. Impact of COVID-19 on lifestyle-related behaviours- a cross-sectional audit of responses from nine hundred and ninety-five participants from India. Diabetes Metab Syndr., 2020; 14(6): 2021-30.

[23]Biasio LR, Bonaccorsi G, Lorini C, Pecorelli S. Assessing COVID-19 vaccine literacy: a preliminary online survey .Hum Vaccines Immunother., 2020; 29: 1304-12. 
